\title{
RENEWABLE ENERGY RESOURCES IN HUNGARY - SOLID BIOMASS UTILIZATION IN TERMS OF NECESSITY AND OPPORTUNITY
}

\author{
Veronika Erős and Tamás Biró
}

Ministry of Rural Development

\begin{abstract}
Annotation. In the 21st century a country's success significantly depends on how it can solve the problems (supply safety, growing prices, climate change, etc.) induced by the application structure of the fossil energy sources with the means of energy saving, energy efficiency and the utilization of renewable energy resources.

The utilization of renewable energy sources has positive effects on five key areas: environment protection, energy policies, fulfilment of EU expectations, agriculture and rural development and on the whole of the national economy.

The bioenergy - beside fulfilling the national economic aims - it is putting up the value of the role of agriculture and rural development. The role of agriculture is multi-functional in the process. The agricultural sector has an important task in the area of bioenergy to ensure the proper quality and quantity of raw materials for the increase of bioenergy utilization. This also means new sales perspectives and opportunities for the producers.

Above all this, the agricultural policy aims for the agriculture and the rural development segment to be the unambiguous winner of the new bioenergy sector and for most of the available profit to stay with the agricultural sector, with the rural players. For this reason encouraging the raw material production it wishes to encourage the producer their primary process and their local utilization.

One of the fundamental objectives of the measures is that agriculture should go beyond the raw material production and take steps towards processing and utilization. The multifunctional role in the product chain might mean extra income and more added value for the producers and the active players in the process.

The other objective is to promote the local utilization, the scatter of the environmentally friendly energy sources in rural areas, to change the energy is "lying on the ground unutilized" principle while local processing and promoting the utilization, to achieve a lower energy dependency and to optimize and disseminate cost efficient solutions. To realize all this means a great task and a huge challenge for the agricultural government as well as the rural societies and micro regions but might lead to a successful rural development.

The range of the tools and measures to fulfil the aims might be very broad, from the regulating instruments to the various subsidies, coordination and dissemination tools. Part of the subsidy schemes are direct production-type of subsidies (the so called direct payments, for example the area based subsidies) and the other main forms are the investment-type subsidies which are for technology development, promotion of competitive production and local processing and for establishing a green energy industry.

In the period of 2007-2013 the key elements of the development schemes were drafted in the frame of the New Hungary Rural Development Programme (ÚMVP) and the Environmental Energy Operational Program (KEOP).

The available raw materials and the conditions are taken into consideration while designing the development schemes because a successful realization of a product chain means the assurance of the inputs and outputs. The starting point of determining the development direction is the principle of an operation which is sustainable and economical on the long run. In addition such developments are considered reasonable which are viable on medium and long term and bring numerous rural development, environmental and societal returns.
\end{abstract}

Key words: Renewable energy resources, Solid biomass utilization

\section{European Union - Hungary. Regulation, objectives, expectations, performance}

The European Union does not have a single energy policy and a closely related implementing policy. The development of a common energy policy is indeed a difficult task since the member states have different regional and environmental properties, and the energy policies of the member states indicating heterogeneous, manifold and complex regulations.

At an EU level there are several objectives and guidelines. They refer to already operative legislations
(Directive 2009/28/EC) and to long term strategic objectives (White Paper, Biomass Action Plan, Climate Strategy, Renewable Energy Roadmap). In these documents the European Union formulated expectations and suggestions to reduce the greenhouse gas $(\mathrm{GH})$ emissions of developed countries by $20 \%$ (comparing 1990 level) until 2020, the carbon dioxide emissions by $30 \%$ until 2020, and $50 \%$ until 2050 .

The Renewable Energy Roadmap and the guidelines clearly indicate the target numbers which aim to have a $20 \%$ share of renewable energy resources by 2020 , including $10 \%$ 
for bio-fuels. For these EU goals and expectations to be realized immediate action is needed, taking into consideration the members states' different geographic and regional characteristics as well as their development potentials.

Based on the above we can state that it is not only Europe but the whole world which is forced to choose an alternative. The challenges of climate changes arising from the ,anthropogenic" GHG emissions originating from the fossil energy utilization have to be solved effectively and urgently. The growing dependence on fossil fuels and rising energy prices make it even more compelling to have a comprehensive and ambitious energy policy which combines the effective and successful action both at a European and at a member state level.

Our common goal is to increase the utilization of renewable energy sources based on agriculture and forestry, to enhance the security of domestic energy supply and to diversify its supply, to sustain development for the profitability of agricultural production, to increase rural employment, to make villages and small towns more sustainable by replacing fossil energy sources and to harmonize the governmental and professional strategies of renewable energy sources while taking into consideration the environment and nature protection aspects.

The national comprehensive targets for the share of energy based on renewable resources of the final energy consumption by the end of 2020 Hungary engaged $13 \%$ (while according to some expert reports $20 \%$ could have been accomplished) which can be achieved by fulfilling the below mentioned aims:

\section{Biofuels, biorefineries}

- $\quad$ Setting up of small, medium and large-scale capacity bioethanol plants with related renewable energy blocks.

- Local use of feedstocks and motivation for public transport use.

- Setting up of medium and large-scale biorefinery plants.

\section{Solid biomass, power plants, local governments, citizens}

- Optimal process and use of biomass deriving from the forestry and the agricultural sector for energetic purposes.

- Direct subsidies for introducing, processing and using of short rotation forestry plantations.

- Setting up of biomass-based district-heating centers to supply individual gas-heated flats and communal buildings.

- Improve the energy efficiency of institutions maintained by local governments and replace the raw materials to renewable biomass.

- Developing of biomass-based small-scale heating power stations to produce electricity and use the waste heat.
- Biomass-based (by-products from the agricultural and forestry sectors, biomass production) small-scale power stations with related agricultural investments (e.g. horticulture).

- Developing of energy farms in order to exploit the advantages of bioethanol, biogas, animal-husbandry and cultivation of arable plants integrated into one system.

- Changing of already existing gas-based districtheating centers and heat centers of industrial or agricultural technologies.

- Replace of co-generated heat centers to biomassbased small-scale power stations associated with the suitable legal and financial environment.

- Developing of biomass-based systems at settlements without gas-systems.

\section{Biogas, bio-methane, pirogas}

- Developing of heat user capacities based on the waste heat of biogas plants.

- Developing of biogas systems, connections of biomethane systems into the national network, development of biogas-based public transport.

- Realization of pirogas micro power stations for electricity and heat production based on locally produced communal waste.

\section{Solid biomass - woody energy plantation, exploitation, and extension}

The natural gas system of Hungary is well developed, $90.8 \%$ of the municipalities have piped gas supply, the combustion machineries are basically modern and well controlled. Despite the increasing price of gas and the periodic difficulties of supply it is difficult to exchange for an alternative kind of energy. The fact should be stressed that more than $70 \%$ of Hungary's gas supply is depending on import.

In Hungary, the $80 \%$ of the total renewable energy use is constituted by biomass. Fifty percent of biomass is composed of firewood. Biomass, as the dominant factor of renewable energy sources, can serve as a basis of their increase. A significant quantity of biomass is still produced in silviculture and wood-based industries, and also in agriculture, that is not or only partially used for energy purposes. The exploitation of these feedstocks and the production of biomass for the utilities can provide a considerable quantity of renewable resources. The areas withdrawn from agriculture allow the production of biomass (energy plantations and other energy plants) in a large quantity. In Hungary, the greatest chance for progress is biomass, including solid biomass and dendromass production; the latter deriving from traditional silviculture and utilizable for energy production.

According to recent forecasts, by 2020, $3992 \mathrm{GWh} /$ year + $50 \mathrm{PJ} /$ year (24 PJ / year for public, $26 \mathrm{PJ} /$ year heating 
systems) of energy should be supplied with raw material, which is estimated to be around 7.8 to 8 million tons of biomass per year (Table 1). In order to produce this quantity we have to rely upon the present stands and new plantings (2010-2015), and the firewood, harvesting losses, agricultural by-products, herbaceous plants from croplands, woody energy plantations, by-products and waste coming from them. A considerable part of this quantity is available in the state and private forests of Hungary.

Table 1: Forecasts for biomass in Hungary for 2020

\begin{tabular}{|l|c|c|}
\hline Biomass Type & Volume (thousand t/ha) & Share (\%) \\
\hline Forest products & 1289 & $16.50 \%$ \\
\hline Felling waste & 490 & $6.27 \%$ \\
\hline Industrial wood waste & 207 & $2.65 \%$ \\
\hline Energy plants & 2305 & $29.50 \%$ \\
\hline Waste - by-product & 3522 & $45.08 \%$ \\
\hline Total & 7813 & $100 \%$ \\
\hline
\end{tabular}

In order to assure the long-term 3-4\% average annual growth rate of gross domestic product (GDP) that represents the economic development, the total energy need of the economy (the energy required to produce a unit of GDP) should be decreased by $3.5 \% / \mathrm{a}$. Such reduction of the energy needs is required to ensure that the annual average growth rate of energy consumption should not exceed $1.5 \%$. As a contribution to meeting this requirement, by 2010 about 75 PJ / year of heat value (1.8 Mt of oil equivalent) should be saved by means of partly state-supported energy-saving activities and exchanged for domestic renewable energy sources. Due to the savings, sulfur dioxide emission can be reduced by $50-55 \mathrm{kt} /$ year, carbon dioxide emission can be reduced by 5-6 Mt / year. The traditional energy sources should be saved, besides, in order to reduce the environmental risks the present use of renewable energy sources should be increased from $28 \mathrm{PJ} /$ year to 65-70 PJ / year by 2015.

Concerning the above, the agriculture has a special place and role. A significant proportion of raw materials for renewable energy come from agriculture and its close environment. The agricultural potential of Hungary suggests that the calculations targeted by European Commission in different segments of bioenergy can be realized by means of a continuous market-focused development strategy. The favourable agro-ecological conditions of Hungary ensure comparative advantage in implementing the EU program.

Taking into account the conditions of our country, biomass plays a determining role within renewable energy sources. This also means that, regarding the progress in the field of renewable energy sources, rural areas will have a higher value, agriculture can be transformed into an energy producing sector, distribution potentials can be widened, and producers can increase their profit.

By means of wood-based energy crops the biomass supply for energy can be improved, that, on the one hand, will relieve forests as a source for biomass, and new crops enable us to create a more rational - more suitable for site conditions - way of crop use, on the other. In addition to various herbaceous and woody energy crops, particular attention should be paid to the collection and use of byproducts and waste (straw, stem, cane, etc).

Besides the national renewable energy use (medium and large electric power stations) local applications are also of special importance (municipalities and their institutions). It is important to note that a great part of renewable energy source is available cheaply, so rural areas can meet a substantial part of their energy needs from their own resources in an environment friendly, cost effective way. With the increasing price of fossil fuels, in the case of the larger energy-consuming agricultural activities (drying, heating of foil tents, poultry farm, etc.) a key to future competitiveness can be an energy supply based on cheap local sources and the substitution of fossil energy in rural, small town and public areas.

With the use of solid biomass for energy and industrial purposes a considerable advantage can be achieved:

- Meeting EU requirements concerning renewable energy sources;

- Diversification of energy supply, decrease of the dependence on oil and gas;

- Using domestic energy sources in stead of import to improve the balance of payment;

- Environmental benefits, reducing CO2 emissions;

- Agricultural benefits, improving farmers income;

- Direct job creation and reservation.

$4,300-4,500$ thousand hectare arable land is used by the cultivation of arable plants, grass land is about 1,600 thousand hectare. 3,300-3,400 thousand hectare agricultural land is available on which the traditional production structure can be maintained, according to professional workshops and significant part of the representations of interests (grain balance, export data, market analysis, etc.). On the basis of all these, an alternative utilization (non-food purpose) has to be fined for a minimum of 1000 thousand hectare land. The most practical form of it is the cultivation of energy crops. It is an important agricultural and a national economic surplus to employ 120-150 thousand people on 1000 thousand hectare land (considering the multiplicative effects). The abandonment of the "usual" cultivation would raise the unemployment in the rural areas. Such huge unemployment layer could not be employed with other rural activities (e.g. tourism, handicrafts, etc.) so the volume and the usage of the cultivation have to be maintained.

The change of the utilization method is reasonable because parts of the affected arable land have unfavourable production circumstances (e.g. danger of inland waters, etc.). These lands are not suitable for profitable production of plants for purposes of the food industry but are suitable for economical energy production.

In the short run (3-5 years), 200 thousand hectare, currently also intensively cultivated land from the minimum needed 1,000 thousand hectare territory for biofuels' raw material production, can be involved into solid biomass production. The suitable land-size can be increased by the alternative use of grass lands and by those lands of energetic purpose that are currently not under the "classical" 
agricultural cultivation. Such territories are the ones indicated for recultivation, short forestry energy plantations beside the roads (quickly growing tree species and also because of road safety reasons it is reasonable to have more flexible species than the ones with massive, thicker trunks) and flooded territories.

By 2020 the raising need of biomass (and wood chips) will, even beside a more intensive collection of waste, be just partly satisfied by the currently available selection.

Considering the given circumstances, possibilities and needs (can vary according to fields and type of users), the biomass-mix tries to find out the balance that is able to assure the needed amount of biomass.

By 2015 the share of short rotation forestry plantation within the biomass mix is 1.6 million tones of wood waste a year. The 1.6 million tones of wood waste a year can be assured by the plantation of short rotation forestry energy plantations.

\section{Employment}

Job creation and keeping of it affects, first of all the agriculture and the rural areas. Collecting of biomass, farming on energetic plantations can solve the problems of a huge amount of uneducated workforce. There is a numerous variety (heating technology, biogas, biofuels) for the use of biomass. Among these, it is considerable to raise our attention to the ones with significant national economic and social effects. The energetic use of biomass can open up new opportunities for integrated systems and for realization of more project units (attitude of solid biomass product range).

To sum up we can say, that thinking according to the attitude of the solid biomass product range, based on the plantation-like forestry, can contribute to the $20 \%$ renewable energy share. The availability, production and use of solid biomass play an important role in the spread of renewables. First of all, the aim is to assure the suitable cultures at territories with worse quality (flood area, sand).

The different short rotation forestry energy plants compared to the "traditional" food plants possess usually with wider tolerance spectrum, so a profitable farming even on unfavourable territories can assure positive economic, social and energetic effects. The key of the success is to choose the suitable and optimal Hungarian growing to the concrete site and market conditions. Growing of energy plants has two aims, on one hand to widen the palette of growing, while on the other hand to assure the needed quantity of raw material.

Considering the above mentioned, fundamental rule is the safe food supply and the order of the energetic utilization because the good-quality arable land demands the healthy production of food raw material, while the territories with less productivity open up opportunities for alternative energy production.

The climate change, the global warming, the worldwide increasing need of energy consumption, the rapid raise of fossil energy resources make the world and Hungary parallel with the members of the European Union act as soon as possible. The diversification of energy resources and the raise of bioenergy-share within the renewable energy share have been a key role. Hungary can benefit from the renewable energy industry by taking the suitable strategic steps and the needed acts while in any other case, we can only be viewers.

\section{References}

Borovics A., L. Nagy (2008): Forest genetic conservation, In. Török K., G. Torda (ed.) Review of biodiversity research results from Hungary that directly contribute to the sustainable use of biodiversity in Europe. Institute of Ecology and Botany of the Hungarian Academy of Sciences, Hungary p. 12-15

Marosi Gy., Mayer B. (2008): Profitability of forestry (wood plantations) for energetic purposes, in Papers of Forestry, Hungary p. 116-118

Rédei K., Osváth-Bujtás Z., Keserü Zs. (2007): Clonal selection of black locust (Robinia pseudoacacia L.) in Hungary: a review, International Journal oh Horticultural Research, 13(3):153-156

Rédei K., Osváth-Bujtás Z., Veperdi I. (2008): Black locust (Robinia pseudoacacia L.) Improvement in Hungary: a Review, Acta Silvatica and Lignaria Hungaria, 4:127-132

Somogyi, Z. (2009): Adaptation to climate change: how should we start?, in Papers of Forestry, Hungary p. 164-167

Bai, A. (2004): Current role and future possibilities of the energetic use of biomass in rural development. Final research communiqué. Identification number of the topic: FKFP 0069/2001. Debrecen

Bai A.-Lakner Z.-Marosvölgyi B.-Nábrádi A. (2002): Utilization of biomass, Szaktudás Publishing House, Budapest, p. 226

Barótfi I. (2005): Energetic utilization of biomass: Investigation of technologies utilizing renewable energies determined by views of a decree of the Ministry of Transport. On behalf of the Energy Centre public utility, Budapest

Biró T. (2009): Renewable energy sources, in the village, volume XXIV.p. 37-44., 3. copy,

Fenyvesi L. - Hajdú J (2006): Complex utilization of biomass

Führer E.-Rédei K.-Tóth B. (2009): Plantation-like wood growing I., Agroinform Publisher, Budapest, p. 245

Juhász Á.-Láng I.-Nagy Z.-Dobi I.-Szépszó G.-Horányi A.-Blaskovics Gy.-Mika J. (2009): Renewable energies. Sprinter Publisher, Budapest, p. 256

Kis Z. (2009): Action Plan of the Programme Office for coordinating rural employment, Budapest, Hungarian Ministry of Agriculture and Rural Development p. 116

Lukács G. S. (2007): Regional Cluster of Green Energies, Károly Róbert College, Gyöngyös, p.181

Propositions of Hungary's Energy Policy 2006-2030 (Commission Paper 2006): Works of Hungarian Electricity JointStock Company, volume XLIII., p. 68

Marosvölgyi B. (2005): Backgrounds of biomass-based energy production, in the VI. Forum for Energy Policy, Hungarian Academy of Sciences, 12th April

Sinóros-Szabó B. (2006): Surplus rural development effects of bioenergy production, p. 1-9. International Conference, Szeged

European Commission (2007): European Strategic Energy Technology Plan - „Towards a low carbon-emission future” COM(2007)0723 final, Brussels, 22nd November

Green Paper for a Community Strategy (1996): - Energy for the future: renewable sources of energy $\operatorname{COM}(96) 576$, Brussels 